\title{
Розробка алгоритму та застосування Maple - програми для визначення траскторії автоматизованого транспортного засобу із заданими параметрами
}

Здійснено за допомогою запропонованих алгоритму та програми опис і побудову узагальненої потенціальної функиї з циліндричними поверхнями на смугах проходження автоматизованого транспортного засобу 3 урахуванням габаритного кола. Визначено, щчо ці результати можуть бути використані при проектуванні систем трасування автоматизованих транспортних засобів і системи автоматизованого врахування та розміщення контейнерів на підприємствах, які спеціалізуються на транспортних операціях із контейнерами загального та спеціального призначення.

Ключові слова: програма, траєкторія, автоматизований транспортний засіб, габаритне коло.

\begin{abstract}
Актуальність
В сучасних умовах існує велика кількість сховищ та площадок, де обслуговування вантажів у формі контейнерів здійснюється автоматизованими системами керування. Виконавцями, що отримують команди від цієї системи, є автоматизовані транспортні засоби (автокари, роботи та ін.), які повинні за оптимальними траєкторіями виконувати свої функціональні задачі 3 переміщення вантажів. Для підприємства, поряд з актуальністю розробки системи обліку й автоматизованого складування контейнерів на площадках та у сховищах, гострою $\epsilon$ потреба в оптимізації руху автоматизованих транспортних засобів у процесі їх виробничої діяльності. Досягається це за допомогою програм, які використовуються в автоматизованих системах керування та дозволяють автоматично визначати траєкторію переміщення автоматизованого транспортного засобу з урахуванням технологічних вимог та перешкод [1-7].

Розробка нових варіантів алгоритмів і програм для автоматизованих систем керування, які зможуть автоматично визначати переміщення автоматизованих транспортних засобів серед вантажів і контейнерів, $є$ сучасною та актуальною.
\end{abstract}

(C) Г.В. Морозова, 2015

\begin{tabular}{ccr}
\hline \multicolumn{4}{c}{ Аналіз літературних джерел } \\
\hline Серед & відомих & алгоритмів \\
оптимальних & траєкторій & переміщення
\end{tabular}
автоматизованого транспортного засобу з урахуванням технологічних вимог та перешкод популярними $\epsilon$ хвильовий алгоритм, алгоритми 3 елементами евристики, алгоритм пошуку шляхів з умовною назвою «Алгоритм $\mathrm{A} *$ » та алгоритм трасування автоматизованих транспортних засобів на базі методу віртуальних потенціалів із використанням мнемонічної моделі. Також існує декілька інструментів досліджень властивостей побудованої поверхні для розрахунку на практиці траєкторії переміщення по площині автоматизованих транспортних засобів з урахуванням кола, яке обмежує його габарити (далі - габаритного кола), і перешкод у вигляді фігур, що належать цій площині [8-10].

\section{Постановка задачі \\ Розробити алгоритм i скласти програму для визначення траєкторії автоматизованого транспортного засобу через побудову узагальненої потенціальної функції з циліндричними поверхнями на смугах проходження автоматизованого транспортного засобу з урахуванням габаритного кола.}

\begin{tabular}{l}
\hline Основна частина \\
\hline Для визначення траєкторії
\end{tabular}


чотирикутників. Структурно об'єднання способів запропонованого підходу до розрахунку траєкторії переміщення по площині автоматизованого транспортного засобу з урахуванням його габаритного кола і перешкод у вигляді фігур виглядає наступним чином:

1. 3 використанням методу Хафа описується рівняннями у неявному вигляді множина прямокутників за координатами вузлових точок, розташованих на площині в околах їх сторін.

2. За допомогою $R$-функцій описується сім'я еквідистант відносно множини прямокутників для визначення відстаней між ними.

3. Описується та будується спеціального виду віртуальна потенціальна функція для заздалегідь заданої точки цілі та множини прямокутників.

4. Визначаються проміжні точки ітерації у процесі визначення траєкторії цільового переміщення «точкового» автоматизованого транспортного засобу за графіком віртуальної потенціальної функції.

5. За допомогою описаної засобами $R$-функцій сім'ї еквідистант визначаються на площині можливі смуги проходження кола заданого радіуса між прямокутними перешкодами.

6. В результаті поєднання способу трасування точки за графіком віртуальної потенціальної функції і способу трасування габаритного кола по площині будується узагальнена потенціальна функція для визначення смуги переміщення автоматизованого транспортного засобу з урахуванням габаритного кола.

7. Визначаються проміжні точки ітерації у процесі руху точки уваги до точки мінімуму в інтерпретації, що важка кулька «скочується» по графіку віртуальної потенціальної функції в межах «коридору», утвореного за допомогою циліндрів, які спираються на можливі смуги проходження кола заданого радіуса на площині між прямокутними перешкодами.

Програма побудови узагальненої потенціальної функції 3 циліндричними поверхнями на смугах проходження автоматизованого транспортного засобу з урахуванням габаритного кола:

a1 $:=3:$ b1 $:=8:$ c1 $:=7:$ d $1:=10$ :

a2 $:=-7:$ b2 $:=-4:$ c $2:=2:$ d $2:=7:$

a3 $:=-5:$ b3 $:=-2:$ c $3:=-5:$ d $3:=-2:$

a4 $:=3:$ b4 $:=8:$ c $4:=-6: \mathrm{d} 4:=-3:$

a5 $:=0:$ b5 $:=5: \quad c 5:=0:$ d5 $:=3$ :

$\mathrm{w}:=0.1$ :

kon $1:=\operatorname{polygon}([[\mathrm{a} 1, \mathrm{c} 1, \mathrm{w}],[\mathrm{b} 1, \mathrm{c} 1, \mathrm{w}],[\mathrm{b} 1, \mathrm{~d} 1, \mathrm{w}]$, $[\mathrm{a} 1, \mathrm{~d} 1, \mathrm{w}],[\mathrm{a} 1, \mathrm{c} 1, \mathrm{w}]]$, color=green, thickness $=3)$ : kon $2:=$ polygon $([[\mathrm{a} 2, \mathrm{c} 2, \mathrm{w}],[\mathrm{b} 2, \mathrm{c} 2, \mathrm{w}],[\mathrm{b} 2, \mathrm{~d} 2, \mathrm{w}]$, $[\mathrm{a} 2, \mathrm{~d} 2, \mathrm{w}],[\mathrm{a} 2, \mathrm{c} 2, \mathrm{w}]]$, color=green, thickness $=3)$ : kon3 := polygon([[a3,c3,w], [b3,c3,w], [b3,d3,w], $[\mathrm{a} 3, \mathrm{~d} 3, \mathrm{w}],[\mathrm{a} 3, \mathrm{c} 3, \mathrm{w}]]$, color=green, thickness $=3)$ : kon $4:=\operatorname{polygon}([[\mathrm{a} 4, \mathrm{c} 4, \mathrm{w}],[\mathrm{b} 4, \mathrm{c} 4, \mathrm{w}],[\mathrm{b} 4, \mathrm{~d} 4, \mathrm{w}]$, $[\mathrm{a} 4, \mathrm{~d} 4, \mathrm{w}],[\mathrm{a} 4, \mathrm{c} 4, \mathrm{w}]]$, color=green, thickness=3): kon5 := polygon([[a5,c5,w], [b5,c5,w], [b5,d5,w], $[\mathrm{a} 5, \mathrm{~d} 5, \mathrm{w}],[\mathrm{a} 5, \mathrm{c} 5, \mathrm{w}]]$, color $=$ green, thickness $=3)$ : plan := display(kon1, kon2, kon3, kon4, kon5, scaling $=$ CONSTRAINED, orientation $=[-90,0]$, axes $=$ NORMAL, thickness $=5$, axesfont $=$ $=[$ TIMES,ITALIC,20]): plan;

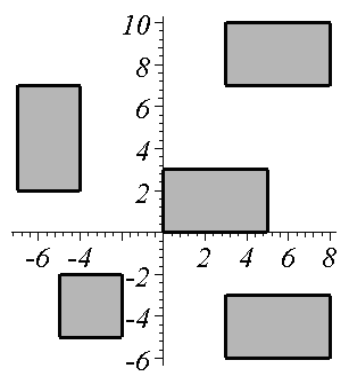

Рис. 1. П'ять заданих прямокутників

xcel $:=10:$ ycel $:=-10$ :

fpot $:=\operatorname{sqrt}\left((\mathrm{x}-\mathrm{xcel})^{\wedge} 2+(\mathrm{y}-\mathrm{ycel})^{\wedge} 2\right)$ :

$\mathrm{z} 1:=\operatorname{sqrt}\left(((\mathrm{a} 1+\mathrm{x}+\mathrm{abs}(\mathrm{a} 1-\mathrm{x})) / 2-(\mathrm{b} 1+\mathrm{x}-\mathrm{abs}(\mathrm{b} 1-\mathrm{x})) / 2)^{\wedge} 2+\right.$ $\left.((\mathrm{c} 1+\mathrm{y}+\mathrm{abs}(\mathrm{c} 1-\mathrm{y})) / 2-(\mathrm{d} 1+\mathrm{y}-\mathrm{abs}(\mathrm{d} 1-\mathrm{y})) / 2)^{\wedge} 2\right)$ :

$\mathrm{z} 2:=\operatorname{sqrt}\left(((\mathrm{a} 2+\mathrm{x}+\mathrm{abs}(\mathrm{a} 2-\mathrm{x})) / 2-(\mathrm{b} 2+\mathrm{x}-\mathrm{abs}(\mathrm{b} 2-\mathrm{x})) / 2)^{\wedge} 2+\right.$ $\left.((\mathrm{c} 2+\mathrm{y}+\mathrm{abs}(\mathrm{c} 2-\mathrm{y})) / 2-(\mathrm{d} 2+\mathrm{y}-\mathrm{abs}(\mathrm{d} 2-\mathrm{y})) / 2)^{\wedge} 2\right)$ :

$\mathrm{z} 3:=\operatorname{sqrt}\left(((\mathrm{a} 3+\mathrm{x}+\mathrm{abs}(\mathrm{a} 3-\mathrm{x})) / 2-(\mathrm{b} 3+\mathrm{x}-\mathrm{abs}(\mathrm{b} 3-\mathrm{x})) / 2)^{\wedge} 2+\right.$ $\left.((\mathrm{c} 3+\mathrm{y}+\mathrm{abs}(\mathrm{c} 3-\mathrm{y})) / 2-(\mathrm{d} 3+\mathrm{y}-\mathrm{abs}(\mathrm{d} 3-\mathrm{y})) / 2)^{\wedge} 2\right)$ :

$\mathrm{z} 4:=\operatorname{sqrt}\left(((\mathrm{a} 4+\mathrm{x}+\mathrm{abs}(\mathrm{a} 4-\mathrm{x})) / 2-(\mathrm{b} 4+\mathrm{x}-\mathrm{abs}(\mathrm{b} 4-\mathrm{x})) / 2)^{\wedge} 2+\right.$ $\left.((\mathrm{c} 4+\mathrm{y}+\mathrm{abs}(\mathrm{c} 4-\mathrm{y})) / 2-(\mathrm{d} 4+\mathrm{y}-\mathrm{abs}(\mathrm{d} 4-\mathrm{y})) / 2)^{\wedge} 2\right)$ :

$\mathrm{z} 5:=\operatorname{sqrt}\left(((\mathrm{a} 5+\mathrm{x}+\mathrm{abs}(\mathrm{a} 5-\mathrm{x})) / 2-(\mathrm{b} 5+\mathrm{x}-\mathrm{abs}(\mathrm{b} 5-\mathrm{x})) / 2)^{\wedge} 2+\right.$ $\left.((\mathrm{c} 5+\mathrm{y}+\mathrm{abs}(\mathrm{c} 5-\mathrm{y})) / 2-(\mathrm{d} 5+\mathrm{y}-\mathrm{abs}(\mathrm{d} 5-\mathrm{y})) / 2)^{\wedge} 2\right)$ :

$\mathrm{p}:=(\mathrm{a}+\mathrm{b}-\mathrm{abs}(\mathrm{a}-\mathrm{b})) / 2$ :

$\mathrm{z}:=\mathrm{p}(\mathrm{p}(\mathrm{p}(\mathrm{p}(\min (\mathrm{z} 1(\mathrm{x}, \mathrm{y})$

$\mathrm{z} 2(\mathrm{x}, \mathrm{y})), \mathrm{z} 3(\mathrm{x}, \mathrm{y})), \mathrm{z} 4(\mathrm{x}, \mathrm{y})), \mathrm{z} 5(\mathrm{x}, \mathrm{y})))$ :

Fpot := plot $3 \mathrm{~d}\left(\operatorname{fpot}(\mathrm{x}, \mathrm{y})+1 / \mathrm{z}(\mathrm{x}, \mathrm{y})^{\wedge} 2\right.$,

$\mathrm{x}=-14 . .14, \mathrm{y}=-12 . .16$,

thickness $=2$, scaling $=$ CONSTRAINED, color=white, axesfont $=[$ TIMES,ITALIC,18], contours $=30$, orientation $=[-130,50]$, style $=$ patchcontour, view $=0 . .36$, axes $=$ BOXED, grid $=[170,170])$ : Fpot;

replot $(\%$, orientation $=[-90,0]$, contours $=30)$;

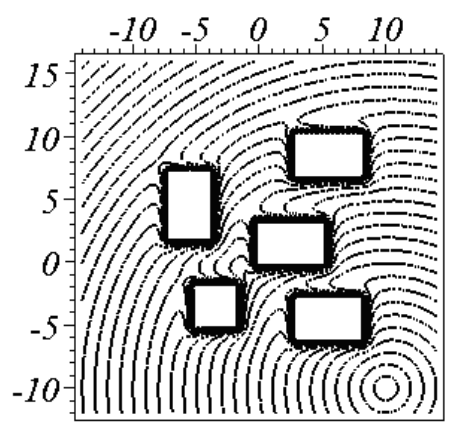

Рис. 2. Лінії рівня віртуальної потенціальної функції 
display(Fpot, plan);

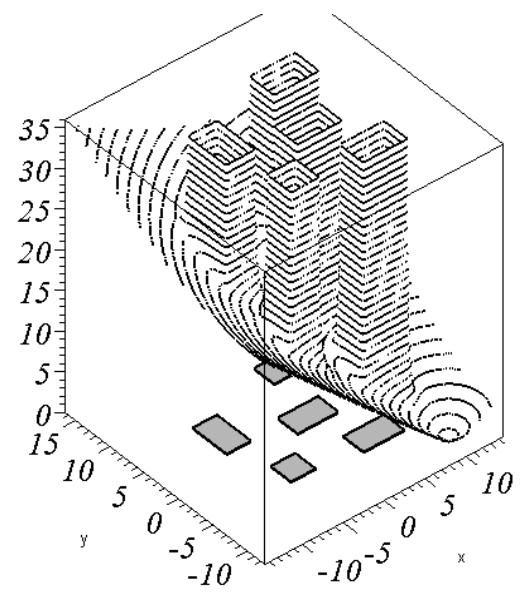

Рис. 3. Графік віртуальної потенціальної функції

$\operatorname{plot} 3 \mathrm{~d}(\mathrm{p}(\mathrm{p}(\mathrm{p}(\mathrm{p}(\min (\mathrm{z} 1(\mathrm{x}, \mathrm{y}), \mathrm{z} 2(\mathrm{x}, \mathrm{y})), \mathrm{z} 3(\mathrm{x}, \mathrm{y}))$,

$\mathrm{z} 4(\mathrm{x}, \mathrm{y})), \mathrm{z} 5(\mathrm{x}, \mathrm{y}))), \mathrm{x}=-14 . .14, \mathrm{y}=-12 . .16$,

thickness $=2$, scaling=CONSTRAINED,

axesfont=[TIMES,ITALIC, 18],

orientation $=[-130,30], \quad$ style $=$ patchcontour, $\quad$ view $=0 . .6$, axes $=$ BOXED, grid $=[170,170])$;

replot $(\%$, orientation $=[-90,0]$, contours $=10)$;

$\mathrm{k} 1:=\operatorname{plot} 3 \mathrm{~d}(\mathrm{p}(\mathrm{p}(\mathrm{p}(\mathrm{p}(\min (\mathrm{z} 1(\mathrm{x}, \mathrm{y}), \mathrm{z} 2(\mathrm{x}, \mathrm{y})), \mathrm{z} 3(\mathrm{x}, \mathrm{y}))$,

$\mathrm{z} 4(\mathrm{x}, \mathrm{y})), \mathrm{z} 5(\mathrm{x}, \mathrm{y}))), \mathrm{x}=-10 . .12, \mathrm{y}=-10 . .12$,

thickness $=2, \quad$ scaling $=$ CONSTRAINED, axes=BOXED, axesfont=[TIMES,ITALIC,18], grid=[130,130],

orientation $=[-90,0], \quad$ color $=$ red,$\quad$ contours $=1$, style $=$ patchcontour, view $=0.2 . .2)$ :

$\mathrm{k} 1$;

unassign('z'),z:

$\mathrm{k} 1:=\operatorname{implicitplot} 3 \mathrm{~d}(\{\mathrm{p}(\mathrm{p}(\mathrm{p}(\mathrm{p}(\min (\mathrm{z} 1(\mathrm{x}, \mathrm{y})$,

$\mathrm{z} 2(\mathrm{x}, \mathrm{y})), \mathrm{z} 3(\mathrm{x}, \mathrm{y})), \mathrm{z} 4(\mathrm{x}, \mathrm{y})), \mathrm{z} 5(\mathrm{x}, \mathrm{y})))=1.5$,

$\mathrm{p}(\mathrm{p}(\mathrm{p}(\mathrm{p}(\min (\mathrm{z} 1(\mathrm{x}, \mathrm{y}), \mathrm{z} 2(\mathrm{x}, \mathrm{y})), \mathrm{z} 3(\mathrm{x}, \mathrm{y}))$,

$\mathrm{z} 4(\mathrm{x}, \mathrm{y})), \mathrm{z} 5(\mathrm{x}, \mathrm{y})))=2\}$

$\mathrm{x}=-10 . .12, \quad \mathrm{y}=-10 . .12, \quad \mathrm{z}=0 . .36, \quad$ thickness $=1$, scaling $=$ CONSTRAINED, color $=$ black, axes $=$ BOXED, axesfont=[TIMES,ITALIC,18],

orientation $=[-130,30]$, style $=$ contour $)$ :

$\mathrm{k} 1$;

display(Fpot, k1, plan);

replot $(\%$, orientation $=[-90,0]$, contours $=10)$.

Одержані результати $\epsilon$ одним із варіантів автоматичного визначення шляху переміщення автоматизованого транспортного засобу між точками площини 3 урахуванням технологічних вимог та перешкод.

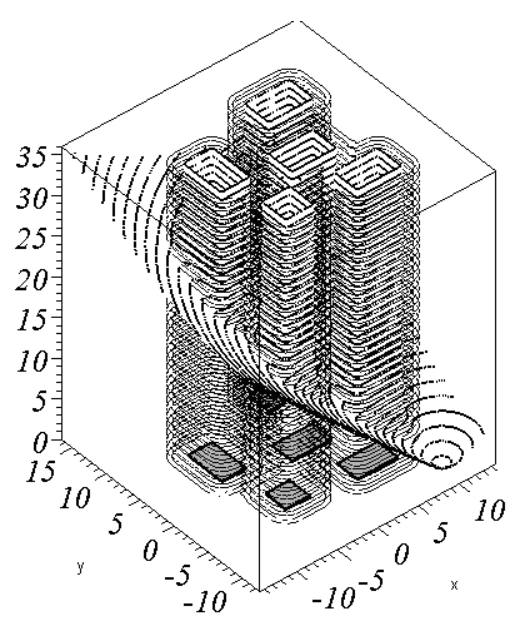

Рис. 4. Графік віртуальної потенціальної функції, суміщений з циліндричними поверхнями зі смугами проходження

\section{Висновок}

Розроблений алгоритм i складену Maple програму можна використовувати при проектуванні систем трасування автоматизованих транспортних засобів і систем автоматизованого врахування та розміщення контейнерів на підприємствах, які спеціалізуються на транспортних операціях із контейнерами загального та спеціального призначення.

\section{Література}

1. Антонов Н. Новые возможности терминалов сбора данных / Н. Антонов // Склад и техника. - 2006. № 1. - C. 18-23.

2. Беспалов Р. С. Транспортная логистика. Новейшие технологии построения эффективной системы доставки. / Р. С. Беспалов - М.: Вершина, 2007. 384c.

3. Васильев М. Ю. Логистика современных систем управления контейнерным терминалом / М. Ю. Васильев, П. А. Аркин, И. Ю. Крылова // Известия СПбГТИ(ТУ). - 2008. - №3 (29). - С. 94-97.

4. Васильев М. Ю. Использование информационнологистических систем в управлении контейнерным терминалом / М. Ю. Васильев // Проблемы современной экономики. - № 1(29). - 2009. - 0.35 п.Л.

5. Васильев М. Ю. Контейнерный терминал: логистика современных систем управления / М. Ю. Васильев, И.Ю Крылова // Экономика и менеджмент: сборник статей.- Санкт-Петербург, СПбГТИ(ТУ), 2009. - Вып. 5. - 0.2 п.л. (авторский вклад -0.1 п.л.).

6. Коган Б.И. Автоматизированные транспортноскладские системы на участках механической обработки деталей: уч. пособие. / - Б.И. Коган. Кемерово: КузГТУ, 2002. - 76 с. 
7. Меламедов Б. Логистика и основы проектирования современного склада / Б. Меламедов // Логинфо. 2007. -№ 6. - С. 24-30.

8. Платонов А.К. Метод потенциалов в задаче прокладки трассы / А.К. Платонов, И.И. Карпов, А.А. Кирильченко - М: Препринт Ин-та прикладной математики АН СССР, 1974. - 27 с.

9. Платонов А.К. Метод потенциалов в задаче выбора пути: история и перспективы. / Платонов А.К., Кирильченко А.А., Колганов М.А. - Москва: И ПМ им. М.В. Келдыша , 2001. - 32 с.

10. Морозова Г. В. Опис положення контейнера для алгоритму трасування шляху мобільного робота / Г. В. Морозова // Інформаційно-керуючі системи на залізничному транспорті. - Харків: УкрДАЗТ, 2011. Вып.1. - С.3-10.

11. Морозова Г.В. Застосування програми автоматизованого проектування для визначення мінімальної відстані між «квадратом» i прямокутниками / Г.В. Морозова // Збірник наукових праць Української державної академії залізничного транспорту. - Харків: УкрДАЗТ, 2014. - Вып.148, ч.2. - С.149-156.
МОРОЗОВА Г.В. РАЗРАБОТКА АЛГОРИТМА И ПРИМЕНЕНИЕ МАРLЕ - ПРОГРАММЫ ДЛЯ ОПРЕДЕЛЕНИЯ ТРАЕКТОРИИ АВТОМАТИЗИРОВАННОГО ТРАНСПОРТНОГО СРЕДСТВА С ЗАДАННЫМИ ПАРАМЕТРАМИ. Осуществлено с помощью предложенных алгоритма и программы описание и построение обобщенной потенциальной функции с цилиндрическими поверхностями на полосах прохождения автоматизированного транспортного средства с учетом габаритного круга. Определено, что эти результаты могут быть использованы при проектировании систем трассировки автоматизированных транспортных средств и системы автоматизированного учета и размещения контейнеров на предприятиях, специализирующихся на транспортных операциях с контейнерами общего и специального назначения.

$\begin{array}{llr}\text { Ключевые слова: } & \begin{array}{c}\text { программа, } \\ \text { автоматизированное }\end{array} & \text { траектория, } \\ \text { транспортное } & \text { средство, }\end{array}$
габаритный круг.

MOROZOVA G. THE DEVELOPMENT OF AN ALGORITHM AND THE APPLICATION OF MAPLE - PROGRAMME TO DETERMINE AN AUTOMATED VEHICLE TRAJECTORY WITH SET-UP PARAMETERS. The description and the construction of the generalized potential function with cylindrical surfaces on traffic lanes where an automated vehicle is to pass taking into account dimensional circle has been performed using the proposed algorithm and the programme. It has been determined that these results can be used while designing automated vehicle location system and mechanical accounting system and placing containers in companies specializing in transport operations with containers of general and special purpose.

Key words: programme, trajectory, automated vehicle, dimensional circle.

Рецензент д.т.н., професор Л.М. Куценко (Національний університет цивільного захисту України) 